\title{
Looking back and glimpsing forward: publication topics in Industrial-Organizational psychology and Organizational Behavior
}

\author{
Andrew C. Loignon • Haley Myers • \\ Steven G. Rogelberg
}

Published online: 9 May 2013

(C) International Network of Business and Management 2013

\begin{abstract}
Industrial-Organizational (I-O) psychology and Organizational Behavior $(\mathrm{OB})$ researchers have periodically reviewed the literature to identify interesting trends and address-specific research questions. We sought to build upon these previous reviews by conducting two studies - a content analysis of the topics and authors from I-O and OB articles published in 2012 (i.e., a look back) and a survey of editorial board members about potential developments in these two fields (i.e., a glimpse forward). Using these two perspectives, we identified some areas within I-O and $\mathrm{OB}$ research that remain popular (e.g., research methodology and psychometric issues, predictors of performance, and work motivation and attitudes), others that continue to emerge (e.g., leadership, diversity, work groups and teams), and some that may be increasingly relevant in the future (e.g., technology). We also noted a relatively small number of practitioners who authored peer-reviewed journal articles and a growing number of authors who are affiliated with non-U.S.-based institutions. These findings correspond with trends from previous reviews of the literature and may have implications for these fields.
\end{abstract}

Keywords Industrial-Organizational psychology · Organizational Behavior · Topics $\cdot$ Trends $\cdot$ Review

\section{Introduction}

As the fields of Industrial-Organizational (I-O) psychology and Organizational Behavior (OB), continue to develop, it is useful to consider the current state and potential future directions of the literature as a whole. Although previous

\footnotetext{
A. C. Loignon $(\bowtie) \cdot$ H. Myers $\cdot$ S. G. Rogelberg

Organizational Science, University of North Carolina at Charlotte, 9201 University City Blvd., Charlotte, NC 28223-0001, USA

e-mail: aloignon@uncc.edu
} 
researchers have reviewed the literature, many of these reviews are more than a decade old, with the most recent being published in 2008 (Cascio and Aguinis 2008). In order to build upon these previous reviews and consider the topics that are currently represented in the literature, we conducted a content analysis of studies from 2012. We also sought to identify future developments in I-O and OB research by surveying editorial board members. Collectively, these two studies provide a look back and a glimpse forward at I-O and OB research in 2012.

\section{Previous reviews}

Earlier reviews of $\mathrm{I}-\mathrm{O}$ and $\mathrm{OB}$ research have identified broad trends within the literature. For example, some reviews have considered the popularity of topical areas within the literature at different time-periods (Cascio and Aguinis 2008; Cox 1977; Campbell et al. 1982). Based on a review of articles published in the Journal of Applied Psychology (JAP), Cox (1977) concluded that psychometrics and personnel selection, appraisal, and training were the most popular topics in both the early 1950s and 1970s. In 1982, Campbell et al. reviewed all of the articles published from many of the top-tier journals in I-O and OB research that year and concluded that the most popular topical area, staffing, accounted for over a quarter of all publications. More recently, Cascio and Aguinis (2008) examined all of the studies published in JAP and Personnel Psychology (PPsych) from 1963 to 2007. Across the two journals, some of the most popular research areas were statisticsresearch methods, performance appraisal-feedback, and job satisfaction-attitudesinvolvement, and commitment.

Rather than conduct a comprehensive analysis of the I-O and OB literature, other reviews have focused on trends within one particular topic area. For example, a recent review considered the popularity of specific theoretical areas within leadership research (Gardner et al. 2010). Between 2000 and 2009, new directions in leadership theories (e.g., ethical or servant leadership, contextual influences on leadership) emerged as the most popular area. Likewise, another review examined descriptions of the employee-employer relationship within I-O and OB research (Roehling et al. 2000). These authors found that articles typically described the employee-employer relationship in a general fashion and ignored important underlying dimensions.

Previous reviews of the $\mathrm{I}-\mathrm{O}$ and $\mathrm{OB}$ literature have also sought to examine the divide between practitioners and academics (Cascio and Aguinis 2008; Strasser and Bateman 1984; Deadrick and Gibson 2007). Researchers have identified significant discrepancies between the publication patterns within academic journals and practitioner-oriented trade outlets. For example, over the course of a decade, practitioner-oriented outlets published 7.24 times as many articles on compensation than academic journals (Deadrick and Gibson 2007). Likewise, an earlier review found that although staffing was a popular topic in the literature, only $5 \%$ of workers who were surveyed felt that this topic should indeed be studied. Instead, these employees placed more emphasis on communication and interpersonal relationships as topics in need of study (Strasser and Bateman 1984). In order to evaluate the practical relevance of I-O and OB research, Cascio and Aguinis (2008) 
also considered how well research publication patterns track with broader historical events. Their results suggest that some topical areas lagged behind historical events (e.g., the passage of the Equal Pay and Civil Rights Acts in the 1960s and the rise in popularity of job analysis and personnel selection), while other areas occurred concurrently (e.g., widespread use of management-by-objectives and studies on performance-appraisal-feedback in the early 1980s).

Finally, previous reviews of the I-O and $\mathrm{OB}$ literature have examined the characteristics of the studies' authors. For example, Cox (1977) identified the most prolific authors in a single journal over two decades. Other reviews have examined the geographic location and affiliation of the studies' authors (Cascio and Aguinis 2008; Gardner et al. 2010). This information helped the authors determine the diversity of authors' nationality and profession (i.e., academic vs. practitioner). For instance, Gardner et al. (2010) found that the majority of authors of leadership research were from the United States and were affiliated with management programs.

\section{Purpose of the current studies}

Each of the previous reviews provided useful and interesting insights about trends within I-O and $\mathrm{OB}$ research. Nevertheless, it has been at least 5 years since researchers have conducted a broad review of the literature (Cascio and Aguinis 2008). Furthermore, these reviews have tended to emphasize historical trends (for an exception see Gardner et al. 2010). Thus, we sought to build upon and update earlier reviews by adopting two perspectives. First, to compare current trends with previous findings, we analyzed the topics that are represented in I-O and OB studies published in 2012. Second, we surveyed a sample of editorial board members about potential future developments in these two fields. These retrospective and futureoriented studies provide unique perspectives of the I-O and OB research in 2012.

\section{Study 1: A look back}

The purpose of the first study was to provide a review of the topics that were represented in articles from three major outlets for I-O and OB research in 2012. We began by adopting a taxonomy from the most recent and comprehensive review of the I-O and OB literature (Cascio and Aguinis 2008). By using an existing taxonomy, we were able to compare our results with the findings of this earlier review. These analyses allowed us to address three research questions, consistent with the goals of previous reviews:

Research question 1: What broad topical areas from I-O and OB research were popular in 2012 and how does the popularity of these areas compare to trends from previous time-periods?

Research question 2: What specific topical areas were popular in 2012 and how comparable are the most recent findings to trends from previous timeperiods? 
Research question 3: How does the geographical and professional characteristics of authors from 2012 compare to those of authors from previous timeperiods?

\section{Method}

We used content analysis to identify broad and specific topical areas within I-O and OB research. This research strategy has been used in previous reviews (Cascio and Aguinis 2008; Gardner et al. 2010; Deadrick and Gibson 2007).

\section{Sample and inclusion criteria}

The sample for the content analysis consisted of articles published in JAP, PPsych, and the Journal of Business and Psychology (JBP) in 2012. These three journals represent major outlets for I-O and OB researchers. In 2011, the impact factor, which represents an index of the number of citations per articles published, for these three journals ranged from 1.25 to 4.31 . Furthermore, two of the journals (i.e., JAP and PPsych) were previously included as part of a comprehensive review of the I-O psychology literature (Cascio and Aguinis 2008).

Similar to previous topical reviews of the literature (e.g., Gardner et al. 2010), we focused on primary articles. Thus, we excluded editorials, special issue introductions, theory letters, book reviews, and interviews. We also excluded advanced online publications of primary articles.

We chose 2012 as a timeframe for a few reasons. First, it is the most recent year with a complete sample of articles and thus corresponds most closely to current trends within the literature. Second, this timeframe begins approximately 5 years following a major review of the I-O psychology literature. Given the pace at which studies are typically published, such a lapse between reviews provided us with an opportunity to examine whether any changes had occurred since the last review.

After applying these criteria, our final sample consisted of 140 articles. The majority of these articles were from JAP $(n=83,59 \%)$. The two remaining journals each accounted for less than a quarter of the sample (JBP, $n=34,24 \%$; PPsych, $n=23,16 \%$ ).

\section{Coding categories}

\section{Primary topics}

We coded the primary topic for each article using a taxonomy from a previous review of the literature (Cascio and Aguinis 2008). This taxonomy was originally developed through an iterative and inductive process and demonstrated sufficient breadth to classify over 5,700 articles, while still remaining parsimonious. The taxonomy consists of 15 broader categories (e.g., career issues) and 50 specific categories (e.g., career-vocational choice-interests, work-family issues). 
Despite the benefits of using an existing taxonomy, we were confronted with a few challenges. First, we found it difficult to define some of the existing categories. In particular, even after conducting an electronic search within the PsycInfo and Business Source Complete databases, we were unable to find an adequate definition for the subcategory "Behavior, prediction of processes, and outcomes." Thus, this subcategory was not used during the independent coding process. Second, a few topic areas were not clearly represented within the taxonomy. For example, topics like well-being, workplace health, emotions, and affect were not clearly identified in the original taxonomy. Thus, in the current study these topics were initially coded within the "Other" category and eventually separated into their own categories. Despite these limitations, the taxonomy still provided a useful framework for the coding process.

\section{Author information}

Finally, we also recorded information about the authors for each article. Specifically, using their reported affiliations, we identified the number of authors who could be classified as academic versus practitioners and who were located within or outside the United States (Cascio and Aguinis 2008).

\section{Coding process}

Each of the articles was coded by the first two authors. To facilitate the interpretation of our results, each article was assigned to a single topical category (Reinard 2008). Prior to coding, we conducted a series of training exercises. Specifically, the first two authors coded two randomly selected articles from each journal from 2007. Thus, each round of practice coding consisted of six articles. During the initial practice rounds, we identified preliminary challenges with the coding process (e.g., coding an article with multiple studies, determining how best to identify the focal topic). After each round, we discussed the differences in our ratings and refined the codebook and decision rules (Weingart 1997). We repeated this process until we demonstrated adequate levels of inter-rater agreement when identifying the primary topic of the six articles (i.e., $>80 \%$ ).

Based on the training process we developed two decisions rules to increase the consistency in which articles were assigned to categories. First, articles were initially coded as "Other" if they did not exclusively or clearly fit into a single subcategory. Articles that clearly fit into a subcategory typically included terms within their titles, key words, definitions, measures, or discussion sections that corresponded to our taxonomy. Articles that were initially coded as "Other" were later reviewed by the first two authors and a final subcategory was determined based on consensus. Second, if an article appeared to focus equally on two topics (e.g., compensation and turnover), we first reviewed the discussion section to see if the authors emphasized one topic more than the other in their review of key findings, implications, or future research areas. If after reviewing the discussion section it was still unclear how to code the article, we considered the primary-dependent variable in the study. If a decision could still not be made following these two decisionpoints, the article was coded as "Other" and reviewed jointly at the end of the 
coding process by the first two authors. This occurred for nearly half of the articles in our sample $(51 \%)$.

Inter-rater agreement

Overall, the level of agreement between the two coders' independent ratings for the primary topics across categories was acceptable (74\%). This level of agreement is comparable to the levels reported in other topical reviews of the literature (Deadrick and Gibson 2007). Disagreements about an article's topic were reviewed jointly and a final decision was reached through consensus.

\section{Results}

Broad topical areas in I-O and OB research from 2012 and a comparison to previous time-periods

Across the three journals, a handful of broad topic areas were popular in 2012 (see Table 1). Specifically, over $64 \%$ of the articles in our sample represented only 6 of the 15 categories. These included research methodology and psychometric issues, leader influences, predictors of performance, societal issues, work groups and teams, and work motivation and attitudes.

Of these six broad areas, three demonstrated levels of popularity that were comparable to those reported in earlier reviews. Specifically, research methodology and psychometric issues, predictors of performance, and work motivation and attitudes were represented in our sample at levels that were comparable to earlier years (Cascio and Aguinis 2008). Thus, it appears that these areas of research continue to be well-represented within the I-O and OB fields.

The remaining three categories, on the other hand, continued to emerge as increasingly popular areas of research. For example, articles within the leader influences category demonstrated a noticeable increase from earlier decades and continued an upward trajectory that began in the mid- to late 2000s. Likewise, studies on societal issues, which primarily consist of research on diversity and stereotypes, demonstrated a similar pattern. That is, beginning in the mid-2000s (8\%) and continuing to the present time-period $(10 \%)$, this research area accounted for a sizeable portion of the total number of publications. Work groups and teams are another category that continued to emerge within the literature. Prior to the 2000s, this category accounted for an average of $2 \%$ of all publications. However, the proportion of publications within this topic area rose to $8 \%$ over the last time-period in Cascio and Aguinis (2008) review and within our 2012 sample.

Specific topical areas in I-O and OB research from 2012 and a comparison to previous time-periods

It may also be useful to consider the specific topics that underlie the broader trends within the I-O and OB literature. In considering the specific topics that were studied 
Table 1 Frequency counts of articles based on broad topical areas for JAP, PPsych, and JBP

\begin{tabular}{|c|c|c|c|c|c|c|c|c|c|c|c|c|}
\hline \multirow[t]{2}{*}{ Broad topic area } & \multicolumn{2}{|c|}{$1963-1967^{\mathrm{a}}$} & \multicolumn{2}{|c|}{$1973-1977^{\mathrm{a}}$} & \multicolumn{2}{|c|}{$1983-1987^{\mathrm{a}}$} & \multicolumn{2}{|c|}{$1993-1997^{\mathrm{a}}$} & \multicolumn{2}{|c|}{$2003-2007^{\mathrm{a}}$} & \multicolumn{2}{|c|}{2012} \\
\hline & $N$ & $\%$ & $N$ & $\%$ & $N$ & $\%$ & $N$ & $\%$ & $N$ & $\%$ & $N$ & $\%$ \\
\hline Job analysis & 13 & 2 & 15 & 2 & 28 & 5 & 4 & 1 & 7 & 1 & 1 & 1 \\
\hline $\begin{array}{l}\text { Research } \\
\text { methodology and } \\
\text { psychometric } \\
\text { issues }\end{array}$ & 129 & 22 & 117 & 18 & 115 & 19 & 249 & 45 & 54 & 10 & 19 & 14 \\
\hline $\begin{array}{l}\text { Predictors of } \\
\text { performance }\end{array}$ & 75 & 13 & 94 & 14 & 84 & 14 & 64 & 12 & 101 & 18 & 15 & 11 \\
\hline $\begin{array}{l}\text { Performance } \\
\text { measurement } \\
\text { and work } \\
\text { outcomes }\end{array}$ & 47 & 8 & 47 & 7 & 80 & 13 & 45 & 8 & 56 & 10 & 8 & 6 \\
\hline $\begin{array}{l}\text { Training and } \\
\text { development }\end{array}$ & 38 & 7 & 27 & 4 & 27 & 5 & 26 & 5 & 19 & 3 & 3 & 2 \\
\hline Industrial relations & 12 & 2 & 3 & 0 & 13 & 2 & 7 & 1 & 7 & 1 & 0 & 0 \\
\hline Reward systems & 13 & 2 & 21 & 3 & 26 & 4 & 10 & 2 & 9 & 2 & 1 & 1 \\
\hline $\begin{array}{l}\text { Work motivation } \\
\text { and job attitudes }\end{array}$ & 74 & 13 & 104 & 16 & 91 & 15 & 50 & 9 & 126 & 22 & 23 & 16 \\
\hline Leader influences & 29 & 5 & 43 & 7 & 25 & 4 & 23 & 4 & 39 & 7 & 18 & 13 \\
\hline $\begin{array}{l}\text { Work groups and } \\
\text { teams }\end{array}$ & 13 & 2 & 15 & 2 & 10 & 2 & 11 & 2 & 46 & 8 & 11 & 8 \\
\hline Career issues & 25 & 4 & 32 & 5 & 15 & 3 & 9 & 2 & 22 & 4 & 6 & 4 \\
\hline Decision-making & 10 & 2 & 17 & 3 & 18 & 3 & 16 & 3 & 24 & 4 & 6 & 4 \\
\hline $\begin{array}{l}\text { Human factors and } \\
\text { applied } \\
\text { experimental } \\
\text { psychology }\end{array}$ & 74 & 13 & 76 & 12 & 34 & 6 & 8 & 1 & 6 & 1 & 0 & 0 \\
\hline $\begin{array}{l}\text { Consumer } \\
\text { behavior }\end{array}$ & 7 & 1 & 19 & 3 & 7 & 1 & 5 & 1 & 7 & 1 & 6 & 4 \\
\hline Societal issues & 18 & 3 & 21 & 3 & 25 & 4 & 23 & 4 & 45 & 8 & 14 & 10 \\
\hline Emotions/affect & & & & & & & & & & & 2 & 1 \\
\hline Well-being health & & & & & & & & & & & 2 & 1 \\
\hline Other & & & & & & & & & & & 5 & 4 \\
\hline Column total & 577 & 100 & 651 & 100 & 598 & 100 & 550 & 100 & 568 & 100 & 140 & 100 \\
\hline
\end{tabular}

The "Other" category includes articles on high-performance work systems, power, negotiation, helpseeking, and moral disengagement

a As reported in Cascio and Aguinis (2008)

in 2012, there appears to be a variety of research areas that are being explored in I-O and $\mathrm{OB}$ (see Table 2). Specifically, researchers studied topics that ranged from absenteeism to work-family issues to creativity and innovation.

A few specific topics appeared to be quite popular in 2012. These include leadership $(n=15)$, work groups and teams $(n=11)$, and diversity and stereotypes $(n=10)$ (e.g., De Jong and Dirks 2012; Walker et al. 2012; Peterson et al. 2012). These three topics accounted for over a quarter of the articles published in our 
Table 2 Frequency counts of articles based on specific topical areas for JAP, PPsych, and JBP (2012)

\begin{tabular}{|c|c|c|c|c|c|}
\hline Specific topic area & $N$ & $\%$ & Specific topic area (cont.) & $N$ & $\%$ \\
\hline Absenteeism, attendance, turnover, retention & 3 & 2 & $\begin{array}{l}\text { Managerial behavior-performance- } \\
\text { interests }\end{array}$ & 3 & 2 \\
\hline Accidents: work, driving, home & 1 & 1 & Motivation-goal setting & 1 & 1 \\
\hline Biographical data & 1 & 1 & $\begin{array}{l}\text { Organizational cultures, climates, } \\
\text { policies, citizenship }\end{array}$ & 8 & 6 \\
\hline Careers-vocational choice-interests & 2 & 1 & Personality assessment & 7 & 5 \\
\hline Communication-counseling & 2 & 1 & $\begin{array}{l}\text { Personnel selection-placement } \\
\text { classification }\end{array}$ & 3 & 2 \\
\hline $\begin{array}{l}\text { Compensation-pay, benefits, incentives, } \\
\text { equity, distributive justice }\end{array}$ & 1 & 1 & Psychometric-testing issues & 3 & 2 \\
\hline Consumer behavior-attitudes-perceptions & 6 & 4 & Recruitment-initial screening & 4 & 3 \\
\hline Counterproductive work behaviors & 4 & 3 & Statistics-research methods & 7 & 5 \\
\hline Criterion issues & 1 & 1 & $\begin{array}{l}\text { Stress, burnout, role conflict, role } \\
\text { ambiguity }\end{array}$ & 4 & 3 \\
\hline Decision-making processes & 1 & 1 & Test validity-validation issues & 7 & 5 \\
\hline Diversity and stereotypes & 10 & 7 & Training, learning, OD, and change & 3 & 2 \\
\hline Emotions/affect & 2 & 1 & Utility analysis & 1 & 1 \\
\hline Generational differences & 1 & 1 & Well-being/health & 2 & 1 \\
\hline Innovation-creativity & 5 & 4 & Work groups-teams & 11 & 8 \\
\hline International applications & 3 & 2 & Work schedules & 1 & 1 \\
\hline $\begin{array}{l}\text { Job satisfaction-attitudes, involvement- } \\
\text { commitment }\end{array}$ & 8 & 6 & Work-family issues & 4 & 3 \\
\hline Leadership & 15 & 11 & Other & 5 & 4 \\
\hline
\end{tabular}

$N=140$. The following specific topical areas were not observed: assessment centers; behavior, prediction of processes, and outcomes; demographic changes; differential validity; disabilities; equal employment opportunity; ethical-privacy issues; genetic screening; interviews; job design; job evaluation-comparable worth; job analysis-classification; legal implications of employment practices; moderator variables; problem solving; unions-industrial relations; work values. The "Other" category includes articles on high-performance work systems, power, negotiation, help-seeking, and moral disengagement

sample. Furthermore, if one combines statistics-research methods $(n=7)$ and test validity-validation issues $(n=7)$, which both emphasize methodology, then these two topic areas also account for a sizeable portion of our sample (10\%) (e.g., Shaffer and Postlethwaite 2012; Bradley-Geist and Landis 2012). Finally, within the broad category of work motivation and job attitudes, articles that focused on job satisfaction, attitudes, involvement, commitment $(n=8)$ and organizational cultures, climates, policies, and citizenship $(n=8)$ were well-represented (e.g., Arthaud-Day et al. 2012; Chang et al. 2012; Mueller et al. 2012).

We also identified a few topic areas that we felt were not adequately represented within the previous taxonomy and merited their own categories. First, diversity and stereotypes $(n=10)$ was not treated as a separate subcategory within the previous taxonomy. However, given that it was one of the most popular topical areas and was distinct from other subcategories (e.g., equal employment opportunity, legal implications of employment practices) (Cascio and Aguinis 2008), we chose to code 
Table 3 Author geographic location and affiliation information

\begin{tabular}{lllllll}
\hline Variable & $1963-1967^{\mathrm{a}}$ & $1973-1977^{\mathrm{a}}$ & $1983-1987^{\mathrm{a}}$ & $1993-1997^{\mathrm{a}}$ & $2003-2007^{\mathrm{a}}$ & 2012 \\
\hline $\begin{array}{l}\text { Geographic location } \\
\quad \text { U.S. location }\end{array}$ & 898 & 1,524 & 1,145 & 1,266 & 1,210 & 333 \\
$\begin{array}{l}\text { Non-U.S. location } \\
\text { U.S.-based authors }\end{array}$ & 50 & 180 & 143 & 187 & 414 & 145 \\
$\quad(\%)$ & 89.44 & 88.90 & 87.13 & 74.51 & 69.67 \\
$\begin{array}{l}\text { Affiliation } \\
\text { Academic affiliation }\end{array}$ & 629 & 1,376 & 1,131 & 1,301 & 1,546 & 449 \\
$\begin{array}{l}\text { Nonacademic } \\
\text { affiliation }\end{array}$ & 323 & 328 & 160 & 141 & 126 & 32 \\
$\begin{array}{l}\text { Academic authors } \\
(\%)\end{array}$ & 66.07 & 80.75 & 87.61 & 90.22 & 92.46 & 93.35 \\
\hline
\end{tabular}

${ }^{a}$ As reported in Cascio and Aguinis (2008)

it as a unique subcategory. Second, counterproductive work behaviors $(n=4)$ were the focus of a handful of articles (e.g., Berry et al. 2012; Ho 2012). Although this specific topic falls within the broader domain of criterion issues, we felt that it worth noting its emergence as a specific topic within I-O and OB research. Other topics, which may have been subsumed in other categories within Cascio and Aguinis' (2008) review, include emotions and affect $(n=2)$, well-being/health $(n=2)$, and generational differences $(n=1)$ (e.g., Costanza et al. 2012; Vijayalakshmi and Bhattacharyya 2012; Robbins et al. 2012). Although, in total, these specific topics account for a relatively small amount of our total sample $(13 \%)$, we believed that their uniqueness and divergence from existing taxonomies merits specific consideration.

Author's geographic location and affiliation

Most authors in our 2012 sample were affiliated with an academic institution and were located inside the U.S (see Table 3). By comparing our findings with Cascio and Aguinis' (2008) results, we see that previously identified trends in the types of authors may still be ongoing. Specifically, fewer practitioners are publishing in these I-O and OB journals $(<7 \%)$. This is down from $13 \%$ in the mid-1980s. On the other hand, it appears that a greater percentage of authors from outside the U.S. are publishing in these journals (more than $30 \%$ ). This proportion of non-U.S. researchers has more than doubled since the late 1990s. Nevertheless, despite the growing involvement of non-U.S. authors, we observed relatively few studies that focused on cross-cultural research $(3 \%)$.

\section{Study 2: A glimpse forward}

The majority of previous reviews of the I-O and $\mathrm{OB}$ literature have relied on retrospective designs in which the content of existing publications was analyzed. 
Although this perspective is useful, it is also interesting to consider where these fields may be heading. Thus, we also surveyed a sample of editorial board members to get their perspective on future developments within I-O and OB research. This survey was designed to answer the following research questions:

Research question 4: What topics will be most relevant within the fields of I-O and $\mathrm{OB}$ research 5 years from now?

Research question 5: What topics will be least relevant within the fields of I-O and $\mathrm{OB}$ research 5 years from now?

\section{Method}

Sample and survey procedure

In order to identify developments in I-O and OB research, we surveyed board members about their perspectives on future research trends. Specifically, we contacted the board members of JBP via e-mail and invited them to complete a brief on-line survey. For background information, we asked board members to identify any additional journals on which they served. We also asked the board members to generally describe their research (i.e., more micro, more meso, or more macro). In terms of their perspectives on research topics, board members responded to two open-ended questions by identifying the topics that they thought would be most or least relevant 5 years from now.

Of the 198 board members we contacted, 63 completed our survey (32\% response rate). On average, these board members provided services for 1.59 journals $(\mathrm{SD}=1.89)$. In total, respondents provided editorial services for 46 different journals (see Table 4). Finally, nearly all board members characterized their research as more micro-oriented (e.g., individual-level) $(n=58,94 \%)$.

Coding responses to open-ended questions

As with the content analysis, the first two authors coded the board members' responses to the open-ended questions. However, for these questions, we adopted an inductive approach. We adopted this approach because we anticipated that, given the future-orientation of the questions that were posed, there was a strong likelihood that the topics identified may diverge from those currently, or previously, represented within the literature; thus the topics may not fit within an existing taxonomy. As such, we jointly identified categories that emerged during the coding process. For each editor's response, we coded the first three topics that were proposed. If more than three topics were provided, we only coded the first three. This helped to insure that a single-board member did not overly influence our results. As we progressed through the data, we refined and revised our coding structure to better represent the data (e.g., collapsed categories). Because we reached decisions through consensus, no measure of agreement was calculated. 
Table 4 Frequency count of journals served by board members

\begin{tabular}{lrr}
\hline Journal name $^{\text {a }}$ & $N$ & $\%$ \\
\hline Journal of Business Psychology & 57 & 89.06 \\
Personnel Psychology & 5 & 7.81 \\
Journal of Applied Psychology & 16 & 25.00 \\
Journal of Organizational Behavior & 13 & 20.31 \\
Journal of Management & 7 & 10.94 \\
Academy of Management Journal & 6 & 9.38 \\
European Journal of Work and Organizational Psychology & 5 & 7.81 \\
Organizational Behavior and Human Decision Processes & 5 & 7.81 \\
Human Performance & 4 & 6.25 \\
Leadership Quarterly & 4 & 6.25 \\
Journal of Personnel Psychology & 4 & 6.25 \\
Journal of Managerial Psychology & 4 & 6.25 \\
Other & 37 & 57.81 \\
\hline
\end{tabular}

$N=63$

a Only journals represented by 4 or more respondents are displayed

\section{Results}

In reviewing the responses of the board members, we chose to highlight the topics that were selected by four or more respondents. Although this limits the breadth of our findings, we felt it would reduce the likelihood of emphasizing chance or spurious results. After applying this criterion, our survey of board members identified a few interesting patterns in future research trends (see Table 5).

\section{Topics most relevant to I-O and $\mathrm{OB}$ research in the next 5 years}

The results for topics most relevant in the next 5 years are summarized in Table 5 . One topic that emerged prominently is technology and social media. Multiple board members believed that the application of technology and social media to human resource management functions (e.g., selection, recruitment) would become increasingly prevalent. Board members also believed that it would be important to consider how technology influences workplace flexibility, motivation, well-being, and communication.

Along with adapting to changes in technology, it also appears that board members believed that $\mathrm{I}-\mathrm{O}$ and $\mathrm{OB}$ researchers will continue to address various issues that organizations and their employees are confronting. For example, workplace well-being, stress, and health, work-life balance, and workplace flexibility, and the aging workforce and retirement were all identified by multiple respondents as topics that would be the most relevant in the next 5 years.

Two types of methodological designs appear to be at the forefront of I-O and OB research. First, multiple board members identified cross-level or multi-level methodology as an approach that will become increasingly relevant in the next 
Table 5 Frequency counts of most and least relevant topical areas identified by board members

\begin{tabular}{lrllrr}
\hline Most relevant & $N$ & $\%$ & Least relevant & $N$ & $\%$ \\
\hline Technology and social media & 13 & 9 & Work attitudes $^{\mathrm{a}}$ & 13 & 22 \\
Workplace well-being/stress/health & 9 & 6 & Leadership $^{\mathrm{n}}$ & 8 & 14 \\
Cross-level/multi-level studies & 9 & 6 & Methodology $^{\mathrm{b}}$ & 7 & 12 \\
Aging workforce/retirement & 8 & 6 & Selection $^{2}$ & 4 & 7 \\
Cross-cultural issues & 8 & 6 & & \\
Work-life/workplace flexibility & 7 & 5 & & \\
Leadership & 7 & 5 & & \\
Diversity/discrimination & 6 & 4 & & \\
Within-person designs & 6 & 4 & & \\
Self-regulation-motivation & 6 & 4 & & \\
Selection-onboarding & 5 & 3 & & \\
Creativity-innovation & 5 & 3 & & \\
Neuropsychology & 5 & 3 & & \\
Emotions-emotional labor & 4 & 3 & & \\
Strategic HRM & 4 & 3 & & \\
\hline
\end{tabular}

Most relevant $-N=144$; least relevant $-N=59$. Only categories that received four or more responses are included

${ }^{a}$ Examples of workplace attitudes that were identified include job satisfaction, perceived organizational support, and organizational commitment

${ }^{\mathrm{b}}$ Examples of methodology that were identified include meta-analyses and single-level studies

5 years. Along with cross-level studies, multiple respondents identified withinperson designs as an important area for future research. That is, studies that assess how individuals change over time or across situations may become more prominent.

In conjunction with our findings from Study 1, board members also believed that research on leadership and diversity-discrimination would be relevant in the near future. For example, board members identified leadership in complex environments and new forms of leadership (e.g., ethical leadership) as relevant topics in the next 5 years. In terms of diversity-discrimination, some respondents mentioned broadening the concepts of diversity and discrimination, diversity issues in internationalization, and salary discrimination as important topics in the next 5 years.

Topics least relevant to I-O and $\mathrm{OB}$ research in the next 5 years

The topic selected by board members to be least relevant in the next 5 years was work attitudes (see Table 5). Within this category, many respondents felt that the seminal work attitudes (e.g., job satisfaction and organizational commitment) would be least relevant. Along with work attitudes, multiples respondents identified leadership as being least relevant in the next 5 years. Similar to work attitudes, the board members who selected leadership as being least relevant tended to emphasize global and more traditional leadership constructs (e.g., transformational or charismatic leadership) in their comments. Finally, board members also identified 
a few methodologies that would be less relevant in the near future. Specifically, multiple board members believed that single-level research would be less influential as the fields of I-O and OB move forward.

\section{General discussion}

As part of this review, we sought to provide two perspectives-a look back at 2012 and a glimpse forward to the next 5 years. Based on these two perspectives, we identified some interesting trends in the popularity of topical areas and author characteristics from articles in 2012 as well as some potential future developments in $\mathrm{I}-\mathrm{O}$ and $\mathrm{OB}$ research. Below, we summarize the main findings from these two studies.

\section{Summary of findings: A look back}

The purpose of Study 1 was to take a look back at articles published in 2012 and identify patterns in broad and specific topical areas, as well as author characteristics. Results suggest that six broad topical areas accounted for a majority of the articles published in 2012. Three of these broad areas have consistently been represented in I-O and $\mathrm{OB}$ research (predictors of performance, research methodology and psychometric issues, and work motivation and job attitudes), while the remaining areas have become increasingly prominent within the past decade (leader influences, societal issues, work groups and teams). In terms of specific topical areas, three topics (i.e., diversity and stereotypes, leadership, and work groups-teams) accounted for over a quarter of the studies published in JAP, PPsych, and JBP in 2012. Nevertheless, we also observed a fair amount of variability in the specific topical areas. Specifically, we identified 40 different specific topical areas in our sample.

In addition to considering the topical trends, we also noted the relatively small number of practitioners who author peer-reviewed journal articles. This finding corresponds with trends from previous reviews of the literature (Cascio and Aguinis 2008). Given the challenges associated with the gap between scientists and practitioners (van Maanen et al. 2007; Van De Ven and Johnson 2006), this finding could serve as a cause for concern. As Cascio and Aguinis (2008) noted, a lack of involvement among practitioners could reduce the quality of I-O and OB research by minimizing its external validity and limiting its overall relevance. Our findings also suggest that a growing number of authors are affiliated with non-U.S.-based institutions. This growing internationalization of the I-O and OB research community could benefit these fields. Specifically, by incorporating research that reflects diverse economies and cultures, the scope of these fields' theories will likely expand.

Finally, it appears that some areas of research, which had previously been at the forefront of I-O and $\mathrm{OB}$ research, may be moving toward the periphery. For example, earlier reviews of the literature had identified performance appraisal and feedback as a popular topic across previous time-periods (Cascio and Aguinis 2008). Nevertheless, we did not identify any studies that focused on this topic during our content analysis. Furthermore, this topic was not mentioned by any of the 
board members we surveyed. Other classic areas of I-O and OB research that were conspicuously absent from our review include traditional predictors of job performance (e.g., assessment center, interviews) and job analysis or job design. Although previous reviews have found these areas to be some of the most popular (e.g., Campbell et al. 1982), they did not emerge within our current review. If these trends continue, it could suggest that researchers are shifting their emphasis to other topics within I-O and OB research.

\section{Summary of findings: A glimpse forward}

Overall, the results of Study 2 suggest that there are a few areas of research that may become increasingly prominent in the next 5 years. The popularity of some of these topic areas may be a reflection of broader changes within organizations. For example, the board members' emphasis on the application of technology and social media to HRM functions likely reflects the proliferation of these new tools. Likewise, as employees and their organizations grapple with shifting demographics and the 24-hour economy, we may have to continue to refine our understanding of workplace well-being, stress, health, work-life and workplace flexibility, and the aging workforce.

Board members also identified within-person and multi-level research methods as being relevant in the next 5 years, which could reflect recent developments that make these approaches more accessible. For example, seminal publications on developing multi-level theory and conducting multi-level analyses have emerged in the past decade (e.g., Preacher et al. 2010; Klein and Kozlowski 2000). Likewise, developments in technology (e.g., surveying via smart phones), methodology (e.g., experience sampling methods), and analyses (e.g., latent growth curve modeling) have made within-person designs much more feasible (e.g., Ployhart and Ward 2011; Ployhart and Vandenberg 2010). Furthermore, the emphasis on these research designs likely reflects the need to capture the complexity of organizational phenomena. The relevance of new methods was also reflected in that multiple board members identified single-level studies as being less relevant in the near future.

Finally, it is interesting to note that two topics, leadership and selection, were identified as being both most and least relevant by at least four board members. These results likely reflect a shared perspective among board members of a need for innovation in these areas. For example, much of the pessimism surrounding leadership was targeted toward well-defined and broad constructs (e.g., charismatic leadership), while those who emphasized leadership in the next 5 years highlighted new facets of this area of research (e.g., ethical leadership).

\section{Limitations}

Although our review of the I-O and OB literature is informative, it does consist of a few limitations. First, our content analysis represents only a single year of articles from three journals. Thus, it is possible that our findings could be susceptible to sampling error. In other words, the frequency counts and percentages for each 
category may fluctuate if we included articles from a longer time-period or from other journals. Thus, we are prohibited in making highly confident conclusions about trends. Nevertheless, by using an existing taxonomy and comparing our findings to those of previous reviews, we were able to examine how findings from our 2012 sample compared to those from previous time-periods (Cascio and Aguinis 2008).

In addition to tentative conclusion regarding trends, the results of our content analysis should be considered as a lagged indicator. Given the amount of time that it takes for an article to be published, it is likely that many of the studies that we analyzed were first conceptualized 3-5 years ago. Thus, the extent to which these findings represent current trends could be questioned. Nevertheless, we sought to mitigate this limitation by collecting additional data from board members. These perspectives are more likely to represent immediate trends within the I-O and OB research and overcome the delay in publishing articles.

Finally, a key limitation with our second study is that the survey of board members may have represented a particular perspective on I-O and OB research. Many of the respondents identified their research as more micro-oriented. It is possible that their responses pertaining to future topic areas may be skewed more toward micro-level topics rather than meso- or macro-oriented research. However, these board members provide services to a wide-range of journals that focus on a variety of topics within I-O and OB research. Thus, it is likely that our sample still provides a useful cross-section of perspectives on future research trends.

\section{Conclusion}

Given how interesting and informative it can be to consider the popularity of research topics, we sought to provide an updated review of recent publications and an assessment of future developments within the fields of I-O and OB. Based on these two perspectives, we can conclude that I-O and OB researchers are engaged in a variety of different areas. We found articles from just this past year that could be categorized into 40 specific topical areas and over 20 broader areas. Likewise, board members identified 16 different areas of research that would be relevant in the near future. Our findings suggest that although there are a few areas of research that account for a sizeable portion of the recent publications, researchers are studying a variety of topics and still have areas for future exploration. We hope that by identifying previous topical trends and potential future developments, we can help members of the I-O and OB fields to continue to propel their research forward.

\section{References}

Arthaud-Day, M. L., Rode, J. C., \& Turnley, W. H. (2012). Direct and contextual effects of individual values on organizational citizenship behavior in teams. Journal of Applied Psychology, 97(4), 792-807.

Berry, C. M., Carpenter, N. C., \& Barratt, C. L. (2012). Do other-reports of counterproductive work behavior provide an incremental contribution over self-reports? A meta-analytic comparison. Journal of Applied Psychology, 97(3), 613-636. 
Bradley-Geist, J. C., \& Landis, R. S. (2012). Homogeneity of personality in occupations and organizations: A comparison of alternative statistical tests. Journal of Business and Psychology, 27(2), 149-159.

Campbell, J., Daft, R., \& Hullin, C. (Eds.). (1982). What to study: Generating and developing research questions. Thousand Oaks: Sage.

Cascio, W. F., \& Aguinis, H. (2008). Research in industrial and organizational psychology from 1963 to 2007: Changes, choices, and trends. Journal of Applied Psychology, 83(5), 1062-1081.

Chang, C. H., Rosen, C. C., Siemieniec, G. M., \& Johnson, R. E. (2012). Perceptions of organizational politics and employee citizenship behaviors: Conscientiousness and self-monitoring as moderators. Journal of Business and Psychology, 27(4), 395-406.

Costanza, D. P., Badger, J. M., Fraser, R. L., Severt, J. B., \& Gade, P. A. (2012). Generational differences in work-related attitudes: A meta-analysis. Journal of Business and Psychology, 27(4), 375-394.

Cox, W. M. (1977). Some changes in articles published in the Journal of Applied Psychology during a 20-year period. Journal of Applied Psychology, 62(2), 241-244.

De Jong, B. A., \& Dirks, K. T. (2012). Beyond shared perceptions of trust and monitoring in teams: Implications of asymmetry and dissensus. Journal of Applied Psychology, 97(2), 391-406.

Deadrick, D. L., \& Gibson, P. A. (2007). An examination of the research-practice gap in HR: Comparing topics of interest to HR academics and HR professionals. Human Resource Management Review, 17, 131-139.

Gardner, W. L., Lowe, K. B., Moss, T. W., Mahoney, K. T., \& Cogliser, C. C. (2010). Scholarly leadership of the study of leadership: A review of the The Leadership Quarterly's second decade, 2000-2009. The Leadership Quarterly, 21, 922-958.

Ho, V. T. (2012). Interpersonal counterproductive work behaviors: Distinguishing between personfocused versus task-focused behaviors and their antecedents. Journal of Business and Psychology, 27(4), 467-482.

Klein, K. J., \& Kozlowski, S. W. J. (2000). From micro to meso: Steps in conceptualizing and conducting multilevel research. Organizational Research Methods, 3(3), 211-236.

Mueller, K., Hattrup, K., Spiess, S., \& Lin-Hi, N. (2012). The effects of corporate social responsibility on employees' affective commitment: A cross-cultural investigation. Journal of Applied Psychology, 97(6), 1186-1200.

Peterson, S. J., Galvin, B. M., \& Lange, D. (2012). CEO servant leadership: Exploring executive characteristics and firm performance. Personnel Psychology, 65(3), 565-596. doi:10.1111/j.17446570.2012.01253.x.

Ployhart, R. E., \& Vandenberg, R. J. (2010). Longitudinal research: The theory, design, and analysis of change. Journal of Management, 36(1), 94-120.

Ployhart, R. E., \& Ward, A. K. (2011). The "quick start guide" for conducting and publishing longitudinal research. Journal of Business and Psychology, 26, 413-422.

Preacher, K. J., Zyphur, M. J., \& Zhang, Z. (2010). A general multilevel SEM framework for assessing multilevel mediation. Psychological Methods, 15(3), 209-233.

Reinard, J. C. (2008). Content analysis of communication. In Introduction to communication research (4th ed.). Boston: McGraw-Hill.

Robbins, J. M., Ford, M. T., \& Tetrick, L. E. (2012). Perceived unfairness and employee health: A metaanalytic integration. Journal of Applied Psychology, 97(2), 235-272.

Roehling, M. V., Cavanaugh, M. A., Moynihan, L. M., \& Boswell, W. R. (2000). The nature of the new employment relationship: A content analysis of the practitioner and academic literatures. Human Resource Management, 39(4), 305-320.

Shaffer, J. A., \& Postlethwaite, B. E. (2012). A matter of context: A meta-analytic investigation of the relative validity of contextualized and noncontextualized personality measures. Personnel Psychology, 65, 445-494.

Strasser, S., \& Bateman, T. S. (1984). What should we study, problems we should solve: Perspectives of two constituencies. Personnel Psychology, 37, 77-92.

Van De Ven, A. H., \& Johnson, P. E. (2006). Knowledge for theory and practice. Academy of Management Review, 31(4), 802-821.

van Maanen, J., Sorensen, J. B., \& Mitchell, T. R. (2007). The interplay between theory and method. Academy of Management Review, 32(4), 1145-1154.

Vijayalakshmi, V., \& Bhattacharyya, S. (2012). Emotional contagion and its relevance to individual behavior and organizational processes: A position paper. Journal of Business and Psychology, 27(3), 363-374. 
Walker, H. J., Feild, H. S., Bernerth, J. B., \& Becton, J. B. (2012). Diversity cues on recruitment websites: Investigating the effects on job seekers' information processing. Journal of Applied Psychology, 97(1), 214-224.

Weingart, L. R. (1997). How did they do that? The ways and means of studying group process. In L. L. Cummings \& B. M. Staw (Eds.), Research in organizational behavior (Vol. 19, pp. 189-239). Greenwich: JAI. 